
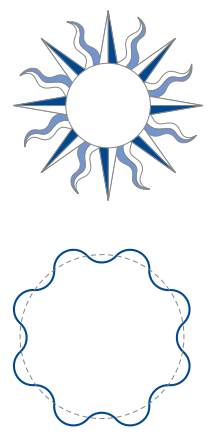

\title{
MERVEILLEUSES STRUCTURES
}

(ㅇ) (0)

Yan Liang

Traduction de Jacques Covès
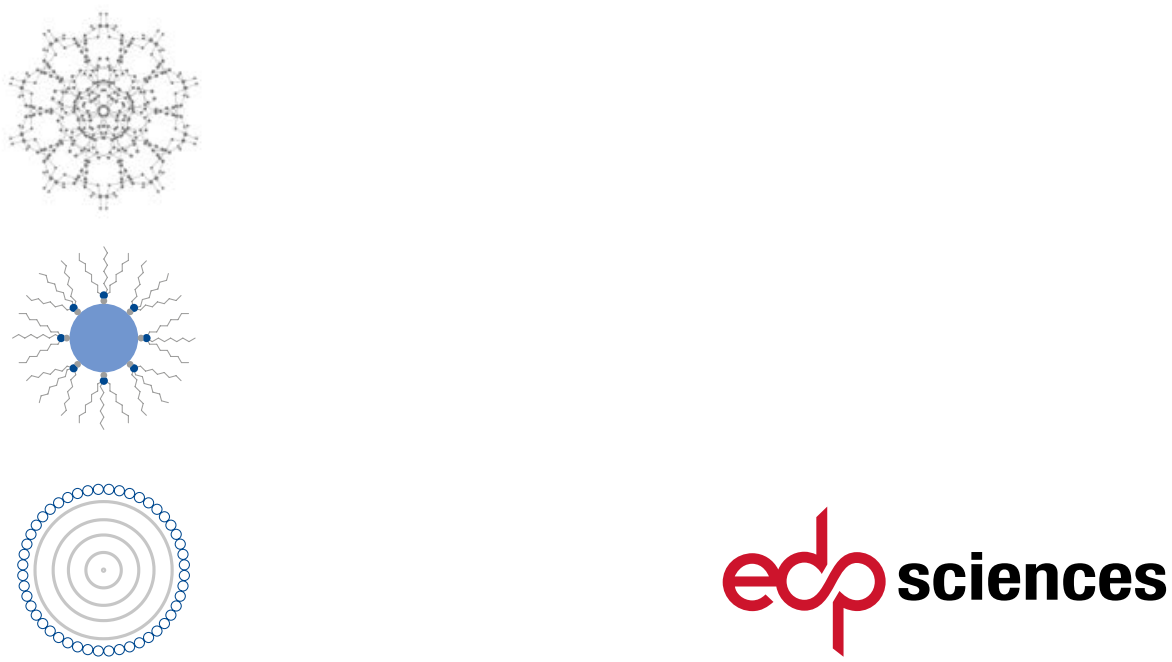
Authorized French translation from the Chinese language edition, entitled Beautiful Structures, 9787302442189 by Yan Liang, published by Tsinghua University Press Limited, copyright ( 2016 . All Rights Reserved.

Imprimé en France

ISBN (papier) : 978-2-7598-2135-8 - ISBN (ebook) : 978-2-7598-2191-4

Tous droits de traduction, d'adaptation et de reproduction par tous procédés, réservés pour tous pays. La loi du 11 mars 1957 n'autorisant, aux termes des alinéas 2 et 3 de l'article 41, d'une part, que les « copies ou reproductions strictement réservées à l'usage privé du copiste et non destinées à une utilisation collective », et d'autre part, que les analyses et les courtes citations dans un but d'exemple et d'illustration, " toute représentation intégrale, ou partielle, faite sans le consentement de l'auteur ou de ses ayants droit ou ayants cause est illicite " (alinéa $1^{\text {er }}$ de l'article 40 ). Cette représentation ou reproduction, par quelque procédé que ce soit, constituerait donc une contrefaçon sanctionnée par les articles 425 et suivants du code pénal. 